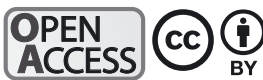

\section{Mean temperature evolution on the Spanish mainland 1916-2015}

\author{
Leire Sandonis ${ }^{1,2}$, José Carlos González-Hidalgo ${ }^{1,2, *}$, Dhais Peña-Angulo ${ }^{3}$, \\ Santiago Beguería ${ }^{4}$
}

\author{
${ }^{1}$ Departamento de Geografía, Universidad Zaragoza, 50009 Zaragoza, Spain \\ ${ }^{2}$ IUCA, Universidad Zaragoza, 50009 Zaragoza, Spain \\ ${ }^{3}$ Instituto Pirenaico de Ecología, Consejo Superior de Investigaciones Científicas (IPE-CSIC), 50059 Zaragoza, Spain \\ ${ }^{4}$ Estación Experimental Aula Dei, Consejo Superior de Investigaciones Científicas (EEAD-CSIC), 50059 Zaragoza, Spain
}

\begin{abstract}
An analysis of the evolution of annual and seasonal mean temperatures on the Spanish mainland (western Mediterranean basin) was carried out, using the new MOnthly TEmperature Dataset of Spain century (MOTEDAS_century) data set. This data set was developed by combining archives from the National Meteorological Agency and newly digitised legacy data from the Annual Books published between 1916 and 1949. Both the annual and seasonal regional mean temperature series experienced increasing trends during the study period. However, the increment was neither constant in time (monotonic) nor homogeneous between seasons. Four main periods were identified in the annual mean regional series. The first 3 corresponded to those previously confirmed in global temperature series (rise-pause-rise); a second pause or hiatus was also detected at the end of the period of analysis. The seasonal regional series followed specific patterns: winter mean temperature only increased in the second rising period, autumn in the first and spring and summer during the 2 rising periods. Also, negative trends were found in extended areas in the first pause in spring, and to a lesser extent in summer. From the middle of the 1980s, the trends in annual and seasonal mean values were not significant up until 2015. Furthermore, spatial variations were found in the significance of the trends, revealing regional differences in the intensity of warming through the seasons. In comparison with other versions of secular mean temperature series developed for the Spanish mainland, MOTEDAS_century seems to better capture the spatial variability.
\end{abstract}

KEY WORDS: Temperature · Trend - Spain · Western Mediterranean basin · MOTEDAS data set

\section{INTRODUCTION}

'If the dark side of concerns about earth's climate is scarce, the bright side is data' (Koutsoyiannis 2020). Climate data from meteorological stations provide the best information available to analyse climate evolution during the last century, to put the current warming processes in a temporal context and to evaluate the output of climate models. Meteorological station information has been used to develop a global climate data set reviewed by Strangeways (2010) and Jones (2016), coupled with many other

${ }^{*}$ Corresponding author: jcgh@unizar.es datasets developed at continental, national and regional scales.

It is well known that available climate information during the pre-remote sensing period is scarce in many parts of the world, and sometimes absent. In addition, a considerable amount of data recorded at many observatories is not available because it has never been digitised. As a result, some researchers have pointed out the importance of data rescue (Folland et al. 2018), given that increasing the spatial density of information reduces the 'structural uncertainty' of climatic time series (Thorne et al. 2005). 
On the other hand, some authors have suggested the eventual redundancy associated with adding more observational data (Jones et al. 2012, Jones 2016). Climate data availability varies in time (Peterson \& Vose 1997) and space (location), with a clear bias in favour of specific elevation ranges and land uses. As a result of these biases in the regional and global series, databases and grids are over-represented in certain regions (such as urban areas), while others are under-represented (Montandon et al. 2011).

Climate information for Spain from the middle of the $19^{\text {th }}$ Century is abundant. This data mostly comes from a global network of observatories managed by the National Meteorological Service, which has been preserving and storing the data for decades. Early data was partially digitised to form the National Spanish Climate database (in Spanish, Banco Nacional de Datos del Clima, BNDC), currently managed by the Spanish Meteorological Service (AEMET). This database has been studied in detail on many occasions and, as expected, research covering long time periods used a small number of stations (Brunet et al. 2006, 2007, Staudt et al. 2007, Sigro et al. 2015). Conversely, recent research, particularly from 1950, has made use of a high number of observatories (del Río et al. 2011, 2012, Ríos-Cornejo et al. 2012, Guijarro 2013, Herrera et al. 2016). In a recent review, González-Hidalgo et al. (2015) highlighted a decreasing number of stations in rural areas during the $20^{\text {th }}$ Century.

However, the BNDC does not include the complete historical records of all meteorological stations. A considerable amount of information has been preserved only in printed format in the Annual Books (in Spanish, Libros Resúmenes Anuales, LRA), published by former Meteorological Services from the start of the meteorological network around 1860 until at least 1950. AEMET has implemented specific actions to preserve the documents in digital format (ARCIMIS project). Still, this legacy data has not been incorporated into the $\mathrm{BNDC}$, nor has the complete information been digitised.

We recently assembled the 'MOnthly TEmperature DAtaset of Spain' (MOTEDAS_century) database of mean temperatures over the Spanish mainland, covering the period 1916-2015. This database was compiled by combining information from the BNDC and the LRA. In a previous work (González-Hidalgo et al. 2020), we described the development of this database and analysed the regional series of the annual means of diurnal (maximum, $T_{\max }$ ) and night-time (minimum, $T_{\min }$ ) temperatures. The results showed a slowdown in an overall increasing temperature trend both for $T_{\max }$ and $T_{\min }$ around the 1980s. In the present work, we analysed the evolution of the Spanish regional series of annual and seasonal mean temperatures, with special emphasis on (1) detecting change over time, (2) identifying the spatial evolution of trends by using a moving windows approach, and finally (3) comparing our results with other versions of secular mean temperature series developed for the Spanish mainland.

\section{DATA AND METHODS}

The MOTEDAS_century database was derived from a combination of BNDC and data digitised from the LRA. After matching both information sources, we calculated a high-resolution grid $(10 \times 10 \mathrm{~km})$ of monthly mean maximum and minimum values for the period 1916-2015. The entire grid consists of 5236 pixels covering the Spanish mainland (Iberian Peninsula, western Mediterranean basin; Fig. 1). A general description of data rescued from the LRA and matched with BNDC along with data processing and grid calculations are described in GonzálezHidalgo et al. (2020), so here we only briefly explain the process.

After digitisation, matching of data series between the 2 sources (BNDC and LRA) was done by directly combining series whose names remained the same in both sources, and manually matching those series that changed but could be related. About $30 \%$ of the data from the LRA were not included in the BNDC. Also, many series from the BNDC were filled in or

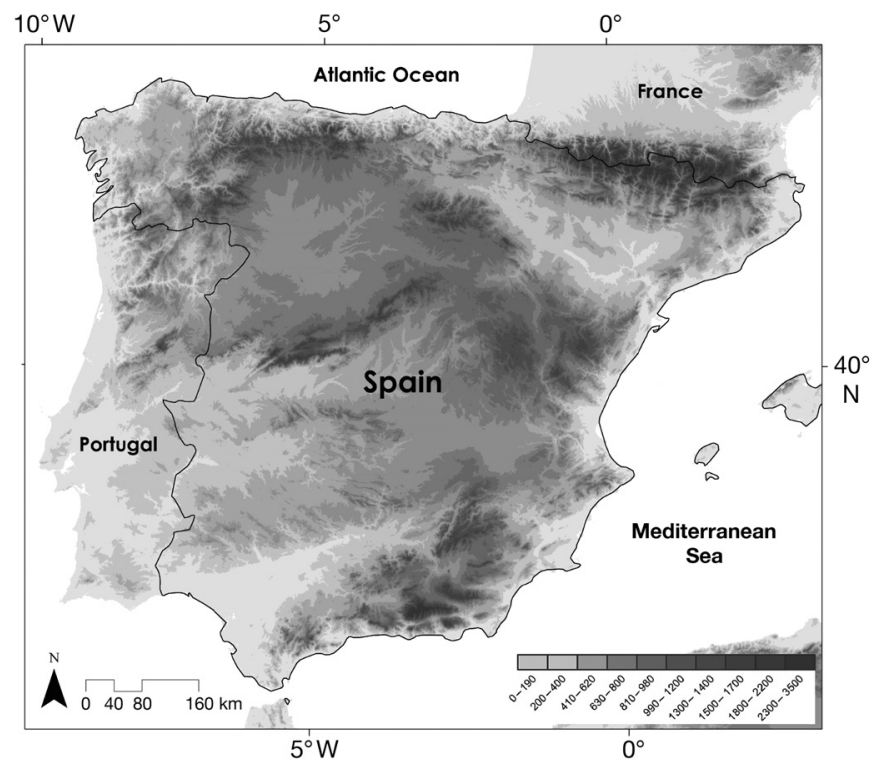

Fig. 1. Study area 
extended using data from the LRA. In total, there are 5259 stations in the MOTEDAS_century database. The number of records available for any given time period varies largely, with a minimum of 228 stations in 1939 (at the end of the Spanish Civil War) and a maximum of 2030 in 1994. Despite this variation in the number of stations, the average distance between neighbouring stations has been stable at approximately $7 \mathrm{~km}$.

One of the most striking characteristics of the data series from BNDC and the LRA is that there are a large number of stations with very short temporal records. Thus, from a total of 5259 observatories recording temperatures from both data sources (19162015), 36.6\% of the total series covers less than $10 \mathrm{yr}$; and there are 3969 series (75.5\%) that cover less than 30 yr (González-Hidalgo et al. 2020). This proportion is higher in the pre-1950 period where, from a total of 1178 observatories (BNDC + LRA), 341 stations between 1916 and 1949 (28.9\% of all stations) recorded $<3 \mathrm{yr}, 475$ (40\% of the series) recorded $<5 \mathrm{yr}$ and 748 stations ( $63 \%$ of the series) $<10 \mathrm{yr}$. In BNDC, 371 stations between 1916 and 1949 recorded <10 yr (55\% of total series). In particular, data from the LRA series are very short: $44 \%$ of stations between 1916 and 1949 recorded $<5 \mathrm{yr}$, and $>70 \%$ of stations recorded temperature data for $<10$ yr (Table 1).

Taking these characteristics into account, and most particularly (1) changes in the number of stations year by year, (2) changes in the location of the stations, and (3) to maximize the amount of information, we decided to develop the grid by performing monthly fields independently and using the total amount of data available instead of reconstructing the series prior to interpolation. Therefore, we used a global approach similar to that described and used in the Reanalysis project (Slivinski et al. 2019). We validated the adequacy of this approach by comparing alternative procedures using filled (reconstructed) and unfilled series. Additionally, 4 interpolation methods were compared using a leave-one-out method. The selected interpolation method was a modification of the one suggested initially by Brunetti et al. (2006), which combined distance weighting and azimuth with original data converted to anomalies based on the 1951-2010 climatology from previous versions of MOTEDAS (Peña-Angulo et al. 2016). Quality control was carried out as a preliminary step prior to interpolation to avoid suspicious data. Detailed information on the advantages and drawbacks of the procedure can be found in González-Hidalgo et al. (2015, 2020).

The annual and seasonal mean series were calculated at a pixel scale from maximum (diurnal, $T_{\max }$ ) and minimum (night-time, $T_{\min }$ ) monthly mean series as $\left(T_{\max }+T_{\min }\right) / 2$, then using the classic seasonal aggregation (December-January-February for winter; March-April-May for spring; June-July-August for summer; and September-October-November for autumn). The regional or national series for the Spanish mainland was calculated as the average $T_{\max }$ and $T_{\min }$ over the whole spatial domain.

We performed trend analyses using 2 complementary techniques. The trend signal and significance were calculated by a non-parametric Mann-Kendall test (Mann 1945); we checked and corrected for any autocorrelation (see González-Hidalgo et al. 2015). The trend rate was calculated by a Theil-Sen estimator (Sen 1968), with the level of significance set at 0.05 .

The regional series of annual and seasonal mean temperature was analysed using temporal windows to detect changes in time. In the time series selected, from 1916-2015 to 1996-2015, the decreasing temporal windows simulated the outcome from the start of the records. The minimum temporal lag (20 yr) was chosen following different authors who have considered the minimum period required to detect any climate signal not hidden by noise (Loehle 2009, Liebmann et al. 2010, Santer et al. 2011, McKitrick 2014). We analysed the temporal evolution of the trends during the period of study by using fixed 30 and $50 \mathrm{yr}$

Table 1. Number of stations and percentage (parentheses) over total amount according to number of years of observations during the period 1916-1949. BNDC: National Climate Data Bank; LRA: Libros Resúmenes Anuales (Annual Books)

\begin{tabular}{|c|c|c|c|c|c|c|c|c|c|c|c|}
\hline & 1 & 2 & 3 & 4 & 5 & $6-10$ & $11-15$ & $16-20$ & $21-25$ & $26-30$ & $>30$ \\
\hline Total & $\begin{array}{c}156 \\
(13.2)\end{array}$ & $\begin{array}{c}103 \\
(8.7)\end{array}$ & $\begin{array}{c}82 \\
(7.0)\end{array}$ & $\begin{array}{c}51 \\
(4.3)\end{array}$ & $\begin{array}{c}83 \\
(7.0)\end{array}$ & $\begin{array}{c}273 \\
(23.2)\end{array}$ & $\begin{array}{c}158 \\
(13.4)\end{array}$ & $\begin{array}{c}147 \\
(12.5)\end{array}$ & $\begin{array}{c}45 \\
(3.8)\end{array}$ & $\begin{array}{c}32 \\
(2.7)\end{array}$ & $\begin{array}{c}48 \\
(4.1)\end{array}$ \\
\hline BNDC & $\begin{array}{c}43 \\
(6.3)\end{array}$ & $\begin{array}{c}42 \\
(6.2)\end{array}$ & $\begin{array}{c}41 \\
(6.0)\end{array}$ & $\begin{array}{c}26 \\
(3.8)\end{array}$ & $\begin{array}{c}51 \\
(7.5)\end{array}$ & $\begin{array}{c}168 \\
(24.7)\end{array}$ & $\begin{array}{c}122 \\
(18.0)\end{array}$ & $\begin{array}{c}111 \\
(16.3)\end{array}$ & $\begin{array}{c}24 \\
(3.5)\end{array}$ & $\begin{array}{c}14 \\
(2.1)\end{array}$ & $\begin{array}{c}37 \\
(5.4)\end{array}$ \\
\hline LRA & $\begin{array}{c}161 \\
(14.5)\end{array}$ & $\begin{array}{c}102 \\
(9.2)\end{array}$ & $\begin{array}{c}88 \\
(7.9)\end{array}$ & $\begin{array}{c}66 \\
(6.0)\end{array}$ & $\begin{array}{c}76 \\
(6.9)\end{array}$ & $\begin{array}{c}314 \\
(28.4)\end{array}$ & $\begin{array}{c}127 \\
(11.5)\end{array}$ & $\begin{array}{c}77 \\
(7.0)\end{array}$ & $\begin{array}{c}35 \\
(3.2)\end{array}$ & $\begin{array}{c}32 \\
(2.9)\end{array}$ & $\begin{array}{c}29 \\
(2.6)\end{array}$ \\
\hline
\end{tabular}


windows to avoid comparing temporal windows of varying length.

Spatial variations in trends were evaluated through sequences of maps covering different temporal windows. Again, the length of the windows was kept fixed to allow for a fair comparison.

\section{RESULTS}

\subsection{Evolution of mean annual and seasonal temperatures (1916-2015)}

The mean annual and seasonal temperature values are given in Fig. 2. This figure shows that the annual mean temperature evolution has not followed a monotonic trend, and 4 periods can be identified (rounded data): (1) rising until ca. 1950, (2) pausestagnation-cooling between 1950 and 1970, (3) a second warming between 1970 and 1990 and (4) a second pause until 2015. Seasonally, spring, summer and autumn are more alike than winter, because the first pause is visually absent in winter. The summer of 1977 is highlighted because of a very low mean temperature.

\subsection{Temperature trend variation in 30 and $50 \mathrm{yr}$ moving windows}

Temporal evolution through 30 and 50 yr moving windows is presented in Fig. 3. As expected, higher variability in trend magnitude is found in the shortest window. Generally, the rates are not significant in $30 \mathrm{yr}$ windows, except in 2 periods: in the middle of the $20^{\text {th }}$ Century, and from the 1980s. In the first case, it can be assumed that the figure detected the first pause due to significant (negative) values in the rates from the 1945-1974 to the 1949-1978 windows. In the second case, the significant (positive) rates begin in the 1963-1992 window and remain until 19802009 (except 1964-1993). From 1981-2010, there are no significant trends in subsequent $30 \mathrm{yr}$ windows until the end of the data set. A second important fact is that the highest rate is found in 1971-2000 $\left(0.589^{\circ} \mathrm{C}\right.$ decade $\left.^{-1}\right)$ followed by a (not always significant) slowdown.

In the sequence of $50 \mathrm{yr}$ temporal windows, we also detected 2 rising periods during the $20^{\text {th }}$ Century, located at both ends of the figure (right and left). The first rising period encompasses 1916-1965 to 19211970 , and the second is evident from the onset in 1950-1999 and remains significant until the end of
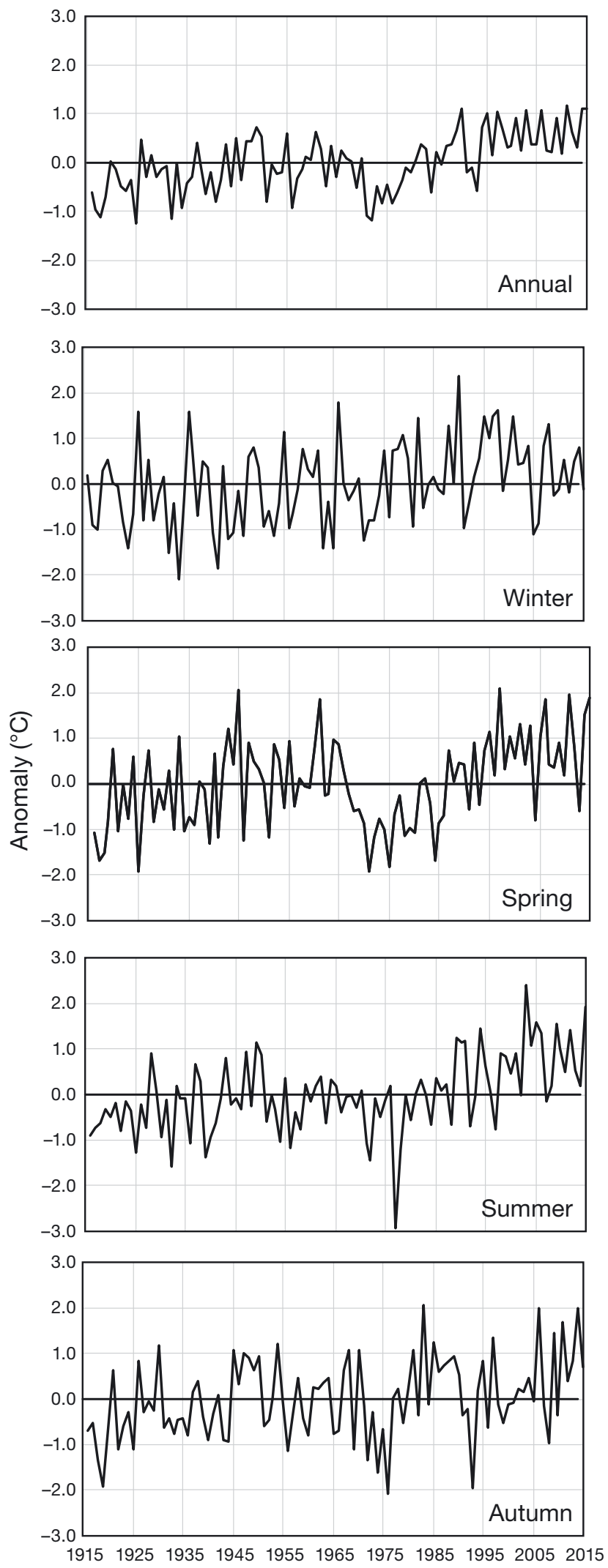

Fig. 2. Regional mean series of annual and seasonal temperatures 

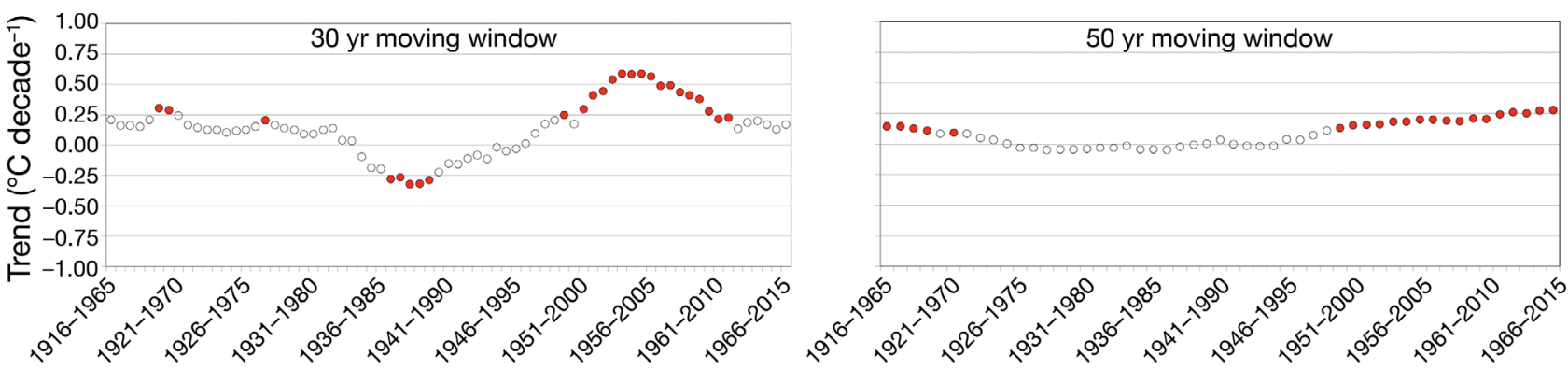

Fig. 3. Annual mean value rate trend $\left({ }^{\circ} \mathrm{C}\right.$ decade $\left.^{-1}\right)$ over $30 \mathrm{yr}$ (upper) and $50 \mathrm{yr}$ (bottom). Filled red circles: $\mathrm{p}<0.05$; empty circles: not significant

the data set. In between both periods, the trend rate is again not significant (1922-1971 to 1949-1998). The maximum rate in $50 \mathrm{yr}$ moving windows is one of the lowest $\left(0.279^{\circ} \mathrm{C}\right.$ decade $\left.{ }^{-1}\right)$.

Fig. 4 shows the evolution of seasonal rates in time using the same 30 and $50 \mathrm{yr}$ moving windows. Once more, it is evident that the variation in rates is higher in the shorter temporal windows, but the figure shows differences in trend evolution across the 4 seasons. The seasonal evolution of rates in $30 \mathrm{yr}$ moving windows shows that the trends are mostly not significant, and there are few significant moving windows. The most striking results are found in spring, when there are significant negative trends (i.e. cooling) in a sequence of windows from the middle of the $20^{\text {th }}$ Century (between 1942-1971 and 1958-1977), and there are significant positive values in recent decades, also in summer. Nevertheless, mean seasonal temperature rates were not significant for a long time period: in winter from 19732002, in autumn from 1948-1977, in spring from 1985-2014 and in summer from 1984-2013.

The same pattern can be found in the $50 \mathrm{yr}$ window analyses, albeit smoothed by the effect of the longer time span. Winter shows significant positive trends in the middle of the century, while in autumn, the only significant trends are found at the beginning and end of the series. Summer is the only season with a constant rise in temperature from the middle of the $20^{\text {th }}$ Century (from 1951-2000), and spring again shows 2 clear positive and 2 negative periods.

\subsection{Trend variation under decreasing temporal windows}

The evolution of the trend rate for annual mean temperature under decreasing temporal windows is shown in Fig. 5, including the 95\% confidence intervals. This analysis provides information on the out- come from the start of records, i.e. the result that would have been produced if climate records had been started earlier. The figure shows a secular increment of the annual mean (left-hand side), and also that the annual mean temperature trend on the Spanish mainland from 1985 to the present (i.e. the last $34 \mathrm{yr}$ ) has not been significant. There is a significant window from 1991-2015, perhaps related to the 2015 El Niño event, but its effects do not remain for a long time. From the maximum value seen in the 1971-2015 windows $\left(0.372^{\circ} \mathrm{C}\right.$ decade $\left.^{-1}\right)$ the magnitude of the trend in annual mean temperature decreases progressively.

The same analysis is shown in Fig. 6 at a seasonal scale. Generally, an overall pattern emerges across the seasons except in autumn, confirming previous results: the rates of seasonal mean temperatures have not been significant during the last 3 decades up to 2015. Thus, the winter trend from 1964-2015, spring rates from 1986-2015 and summer from 19842015 were not significant. The data for autumn is highly irregular, and shows a brief rise in recent decades, but has not been significant since the 1970s.

A second prominent result is the global context of rate evolution: except for the autumn rates, the seasonal trend in magnitude slowed down from the maximum values reached around the 1970 s, which were seen in temporal windows that differ between seasons; the minimum length is over the requirements set by different researchers (see Section 2).

\subsection{Spatiotemporal variations of trends}

Fig. 7 shows the evolution of the percentage of land classified by the sign (+ or -) and significance of the trend, using temporal windows of 30 and $50 \mathrm{yr}$. The annual mean trend shows the sequence of the 4 periods mentioned above, with the second rise in temperature more intense and extended than the first. Also, 


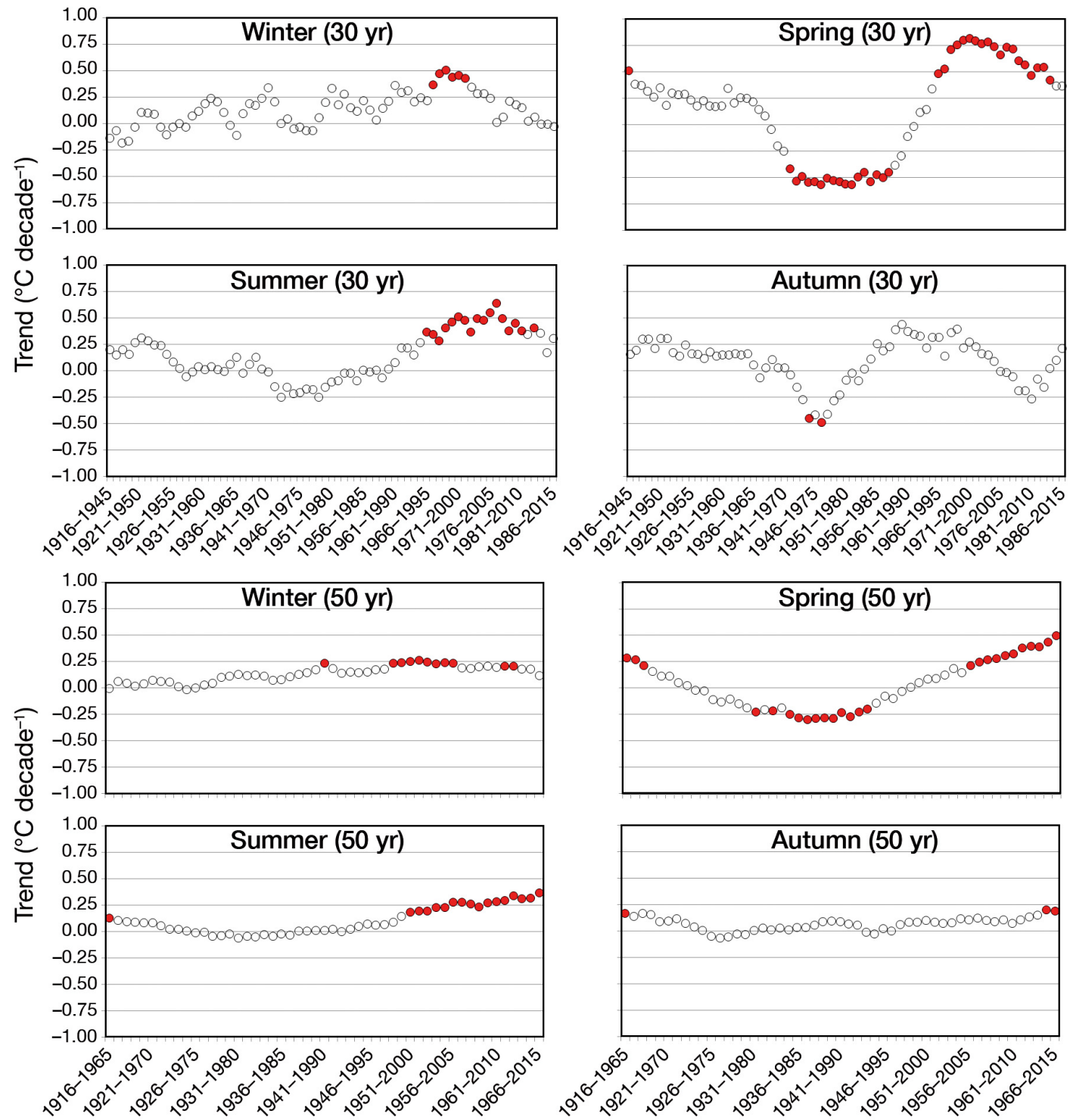

Fig. 4. Seasonal mean value rate trend $\left({ }^{\circ} \mathrm{C}\right.$ decade $\left.^{-1}\right)$ over $30 \mathrm{yr}$ (upper) and 50 yr (bottom). Filled red circles: $\mathrm{p}<0.05$; empty circles: not significant
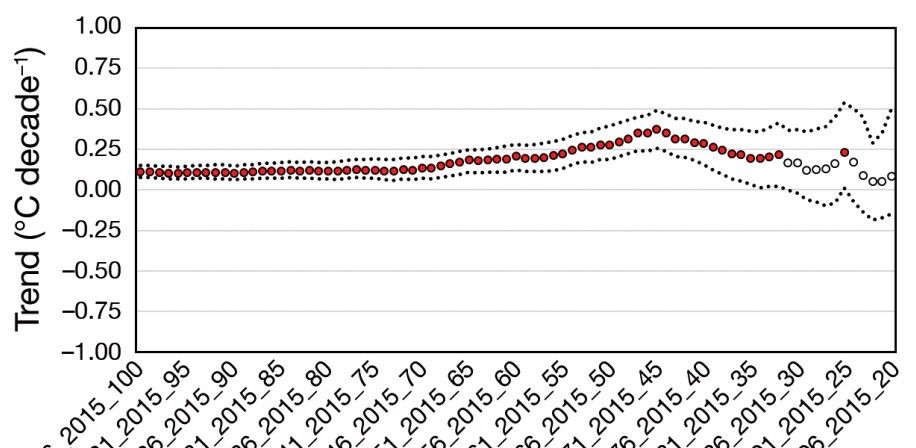

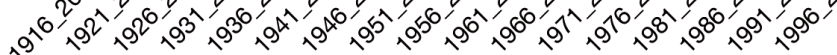

Fig. 5. Variations of annual mean temperature trend rate $\left({ }^{\circ} \mathrm{C}\right.$ decade $^{-1}$ ) under decreasing temporal windows. Filled red circles: $p<0.05$; empty circles: not significant; dotted lines: $95 \%$ confidence intervals the first pause around the 1940s is seen as a negative and significant rate over an extended area. The second pause is also evident, affecting more than $75 \%$ of the territory.

Seasonal analyses identify different temporal patterns. In winter, only the second rising period is detected. In spring and summer, both rising periods are spatially generalised, while in autumn only the first rising period is detected. Furthermore, spring and summer differ in the first pause, being more intense and extended in spring than in summer; the same is true for the second rising period. Similar results were found using $50 \mathrm{yr}$ moving windows. In contrast with 


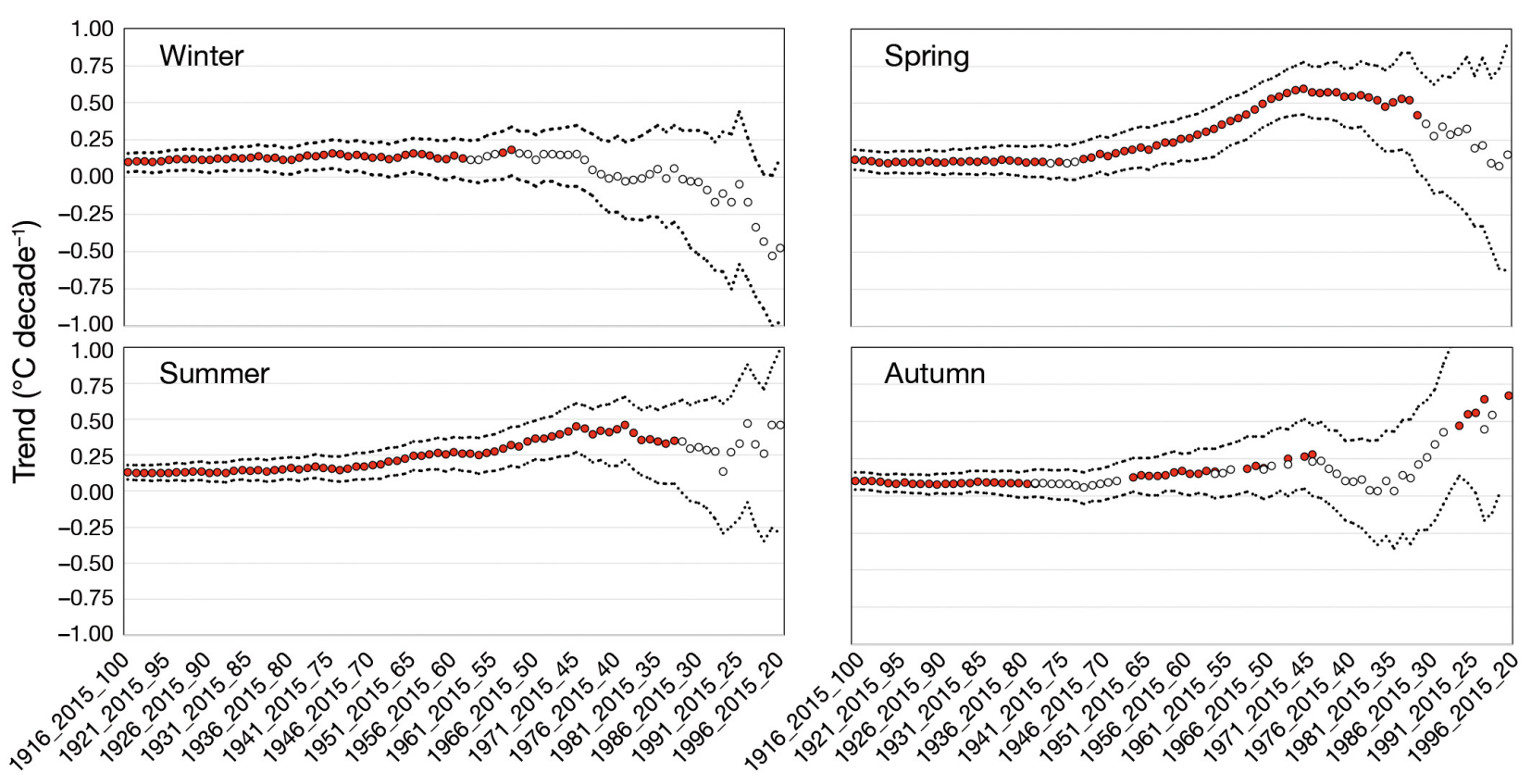

Fig. 6. Variations in seasonal mean temperature trend rate $\left({ }^{\circ} \mathrm{C}\right.$ decade $\left.^{-1}\right)$ under decreasing temporal windows. Filled red circles: $\mathrm{p}<0.05$; empty circles: not significant; dotted lines: $95 \%$ confidence intervals

$30 \mathrm{yr}$, in $50 \mathrm{yr}$ moving windows the recent pause in spring and summer is hidden, whereas it is augmented in winter and autumn.

The sequential maps using $30 \mathrm{yr}$ moving windows show spatial variations of both significance and sign (+ or - ) at annual and seasonal scales (Fig. 8). Seasonal trends show different behaviours between seasons. Winter signs were mostly negative (albeit not significant) during the first rising period, affecting central and western areas; and positive and no significant trends were detected from 1974-2003. Spring and summer clearly show the sequence of rise-pauserise-pause periods, being more extended and intense in spring than in summer both in the first positive period and pause. In spring and summer, the areas with significant trends are mostly located in the central-eastern Iberian Peninsula. No significant trend is detected in spring from 1984-2013 except in small areas in the southeast, and from 1985-2014 in summer. Finally, autumn clearly shows an extended area during the first pause with a significant negative signal.

As a consequence of the abovementioned seasonal behaviour, it can be said that the annual evolution of the temperature trend is mostly due to spring and summer. Also, the areas with positive and significant trends using $30 \mathrm{yr}$ windows are primarily located in the central-eastern part of the Iberian Peninsula. Irrespective of the significance of the signal, positive trends are localised predominantly to the east, whereas the reverse is true for negative trends.

\subsection{MOTEDAS_century and other versions of Spanish mainland temperatures}

Different data sets have been used to calculate regional secular land temperature series. Therefore, to validate and perform a final evaluation of the new MOTEDAS_century data set, we compared the results of the original data set with previous versions of annual and seasonal series for mainland Spain. The data sets compared were SDAT (Sigró et al. 2015), the national series performed in the BEST data set (Rohde et al. 2013) and the series from the $20^{\text {th }}$ Century Reanalysis from $35^{\circ}-40^{\circ} \mathrm{N}$ and $5^{\circ} \mathrm{W}-5^{\circ} \mathrm{E}$ coordinates (Slivinski et al. 2019); Fig. 9 shows the difference in the annual means between these 3 data sets and the MOTEDAS_century.

Generally, MOTEDAS_century has a more stable relationship over time with BEST and Reanalysis, rather than SDAT; the differences in annual mean value with this data set gradually diverge from the middle of the 1970s.

Table 2 shows the evolution of annual mean rates under decreasing temporal windows (5 yr intervals) during the common period 1916-2012 (BEST is not updated after 2012 and SDAT after 2014). The trends 


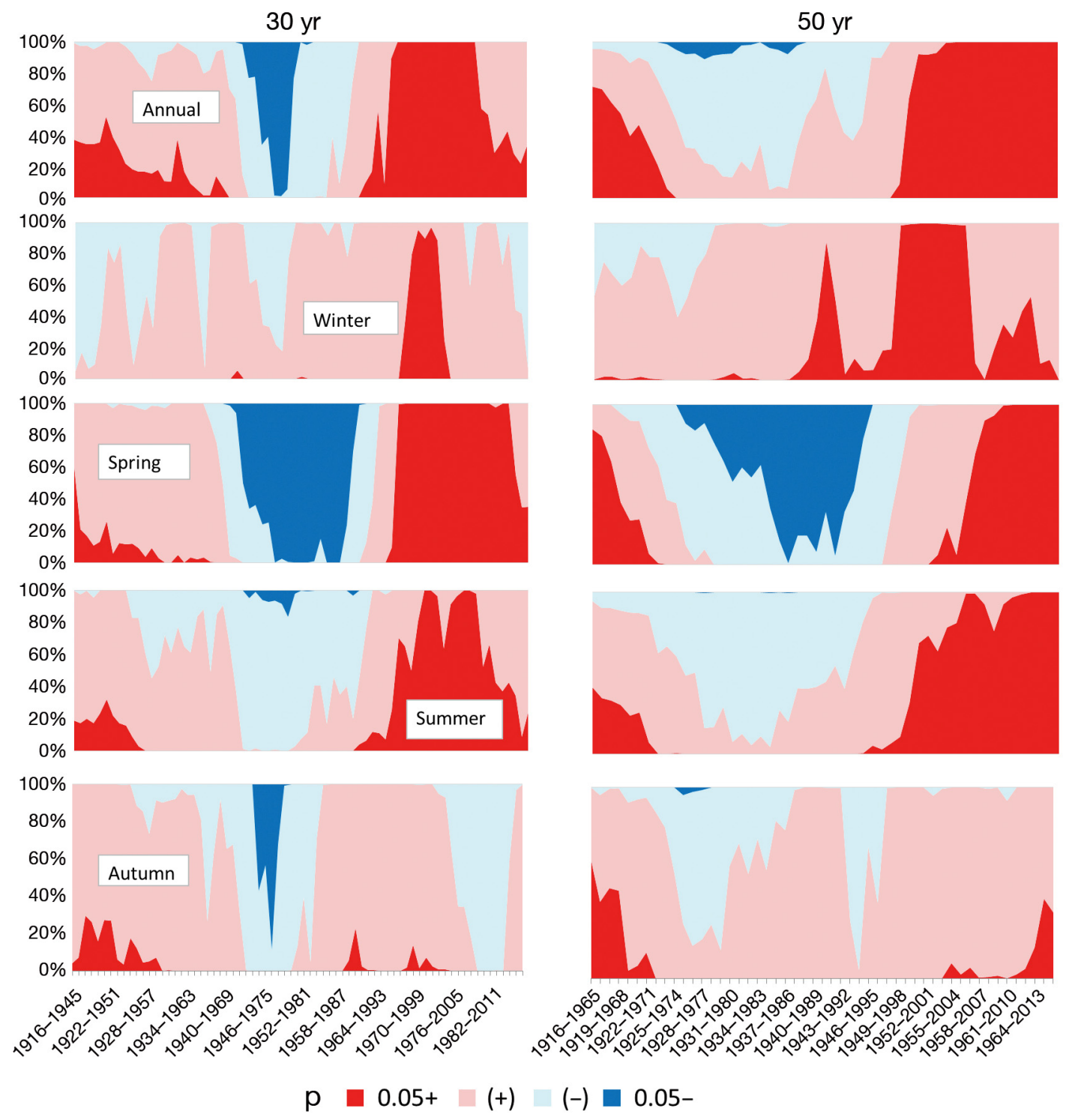

Fig. 7. Spatial analyses of 30 and 50 yr temporal windows. Percentage evolution of land according to signal and significance of trend. Significance level: $\alpha=0.05$

are not significant in the 1986-2012 window except in SDAT, and there is a clear slowdown (attenuation) in the magnitude of the trend in the 4 versions. SDAT gives the highest rates in any temporal window.

The evolution of the 4 versions is similar, so these results show the global frame for secular variation of annual mean temperature on the Spanish mainland, with differences mostly relating to the magnitude of the trend.

In short, the annual mean temperature evolution on the Spanish mainland in the $20^{\text {th }}$ Century can be summarised as follows: (1) a global rise in annual mean temperature is confirmed at a rate of $\sim 1^{\circ} \mathrm{C}$ century ${ }^{-1}$ in BEST and MOTEDAS_century, but is higher in SDAT at $\sim 1.5^{\circ} \mathrm{C}$ century $^{-1}$ and lower in Reanalysis at $<1^{\circ} \mathrm{C}$ century ${ }^{-1} ;(2)$ there is a maximum rising period in annual mean temperature starting around the 1970s and lasting for several decades, at a rate of $>3^{\circ} \mathrm{C}$ century ${ }^{-1}$ in BEST, Reanalysis and MOTEDAS_century, and increasing to $>4^{\circ} \mathrm{C}$ century ${ }^{-1}$ in $\mathrm{SDAT}_{\text {; }}$ (3) there is no significant rate evident in the last few decades, from 1981 in BEST, Reanalysis and MOTEDAS_century, and from 1991 in SDAT; and (4) a progressive slowdown of the annual rate in the 4 versions is seen after the maximum in the 1970s.

Table 3 shows the same analyses at seasonal scales. Once again, the seasonal pattern of mean temperatures is similar among the 4 versions, and SDAT usually shows the highest values. In all 4 seasons, the mean temperature values confirmed that intensity has 

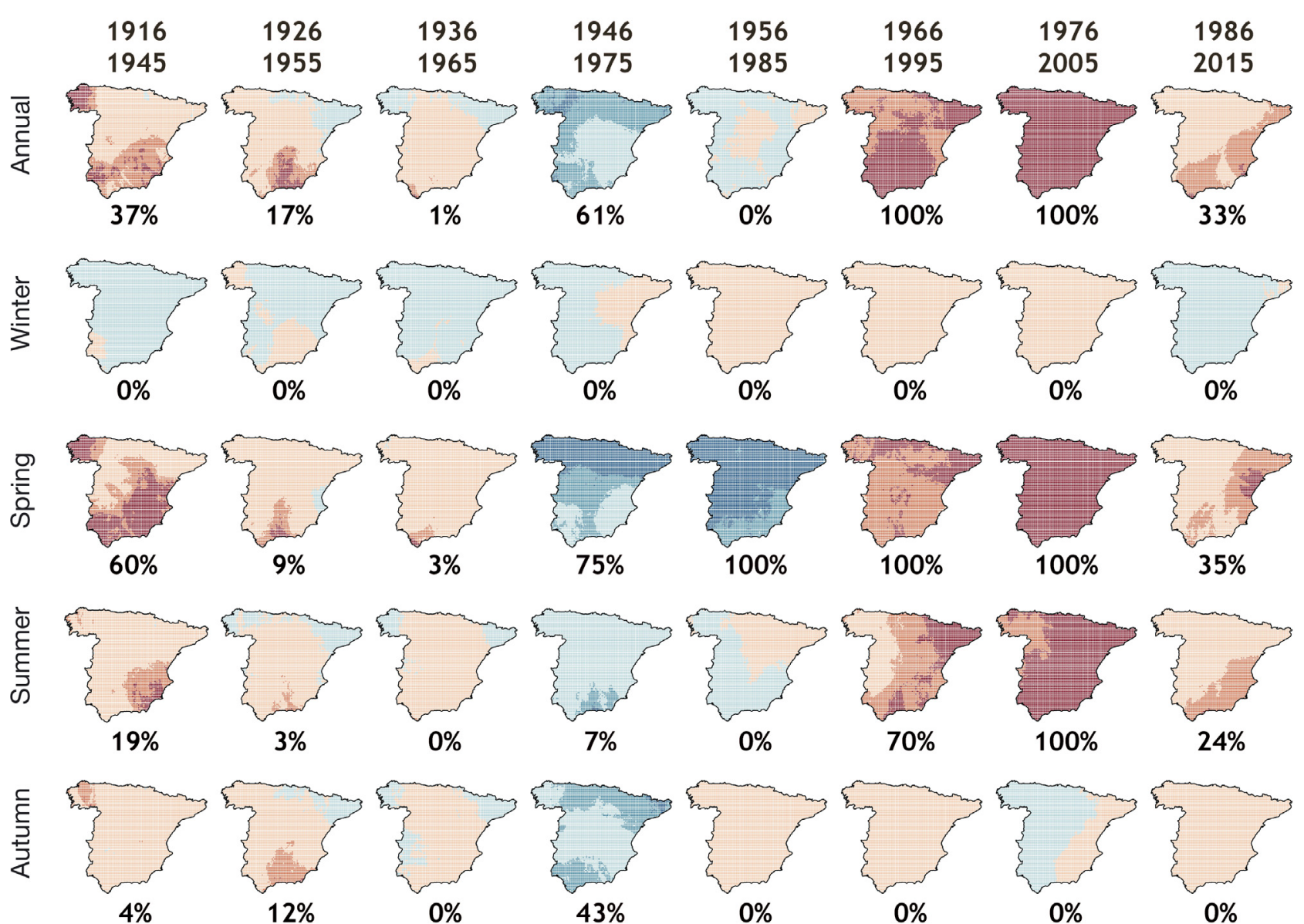

$0 \%$

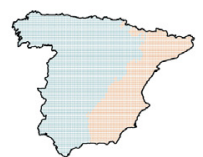

$0 \%$

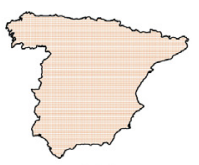

$0 \%$

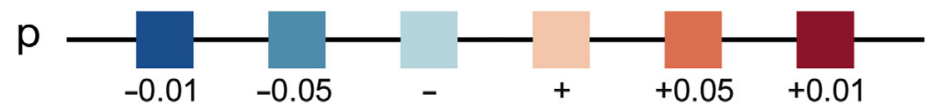

Fig. 8. Spatial trend evolution at selected temporal windows (30 yr). Percentages show the areas under significant trend ( $\mathrm{p}<0.05)$. Red/blue: positive/negative trend; strong/light: significant/not significant

been decreasing for decades; furthermore, except in the summer SDAT series, the rates have not been significant for the last $25 \mathrm{yr}$. The data for winter is surprising, as the rate of the mean temperature value has not been significant over the last 40 yr. Negative values were detected in the last few decades in the winter series, and also in autumn. Finally, maximum values were identified in spring and summer in windows that started in the 1970s, and are usually higher in the SDAT data set than the others.

In brief, the analyses of trend evolution of the seasonal mean temperature series on the Spanish mainland detected the final pause of the $20^{\text {th }}$ Century, which was verified in the 4 versions of the Spanish regional series for different reasons: (1) trends were not significant for more than 2 decades, (2) the magnitude of trends decreased after the 1970s maximum and (3) there were some windows with negative trends, although these trends were not significant.

\section{DISCUSSION}

In the present study, we have shown results from a new data set (MOTEDAS_century) which uses the highest spatial density of information presently available, particularly for the pre-1950 period, after a massive data rescue. Jones et al. (2012) and Jones (2016) suggested that, because climate series are not mutually independent, increasing the number of stations in a given data set would only introduce redundancy without significantly decreasing the overall uncertainty. Our opinion is that redundancy would be produced mostly (1) with spatially aggregated 


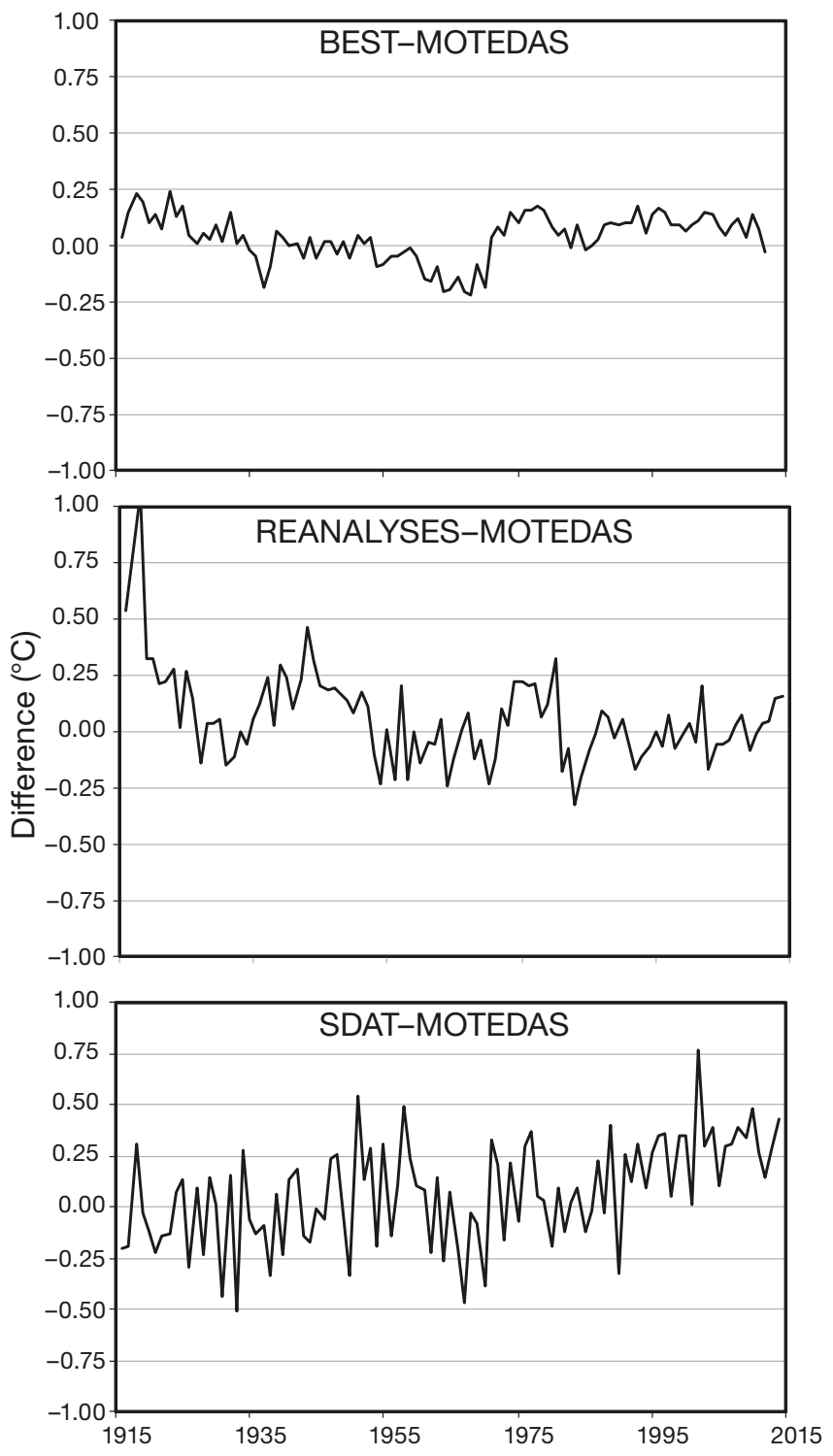

Fig. 9. Annual mean temperature series. Comparison of BEST, Reanalysis and SDAT with MOTEDAS_century (differences)

(clustered) stations; (2) if stations were reconstructed; and (3) in the case of an isotropic spatial behaviour. These 3 suppositions, however, are not met - at least in the Spanish conterminous land - because the spatial distribution of the stations changes over the years, and because the grid was developed by reconstructing monthly fields, not by reconstructed individual series. The global results and the temporal analyses of trends presented here suggest that the new grid of Spanish mainland temperatures do not include redundancy due to the following reasons: (1) during the early part of the $20^{\text {th }}$ Century, data rescue incorporates information absent in many areas; (2) consequently, MOTEDAS_century avoids having to interpolate missing values using very distant points, mainly related to the same land-use type (mostly urban and other artificial surfaces) during the early decades; (3) towards the end of the century, particularly after 1950, the management of complete information includes the spatial diversity of stations, which are conditions not usually found in other versions; and (4) MOTEDAS_century only analysed original data, not including reconstructed series, which is an additional source of redundancy.

It is interesting to note that Peña-Angulo et al. (2015) showed that the Spanish mainland has a high spatial variability of temperature regimes, and common variance higher than $50 \%$ is reached at distances of $<50 \mathrm{~km}$. Consequently, a real effect from a larger number of stations, as in MOTEDAS_century, is a decrease in spatial uncertainty. This increased spatial coverage and decreased uncertainty was one of the principles driving the development of MOTEDAS_ century, along with an ongoing goal to develop the grid using monthly fields instead of reconstructed series.

The global mean temperature has risen around $1{ }^{\circ} \mathrm{C}$ from the beginning of the $20^{\text {th }}$ Century (Allen et al. 2018). This rise was not uniform and occurred over a sequence of 3 periods: (1) rising during the early decades, (2) pause after WWII until the 1970s, (3) a second rising period until at least the 1990s (see Easterling \& Wehner 2009, Foster \& Rahmstorf 2011, Kaufmann et al. 2011), with (4) a second pause until the present day being under discussion (Medhaug et al. 2017, Tung \& Chen 2018).

Comparison among different versions of annual mean temperatures in the Spanish mainland throughout the $20^{\text {th }}$ Century and global series suggests that the new MOTEDAS_century grid produced from monthly fields did not introduce anomalous results or bias in the final series. This can be seen by the similar temporal pattern at the annual scale; the 3 initial phases can be seen in MOTEDAS_century, the same as in the other versions (rise-pause-rise); however, apparent similarities hide differences among versions, particularly in recent decades. Also, the final pause up to 2010 detected in the previous version of MOTEDAS (González-Hidalgo et al. 2016) lasted until 2015 in MOTEDAS_century.

Generally speaking, as the number of stations increases, the global mean value of the final series decreases, along with the trend. The SDAT mean series is derived from 22 observatories, all of which are qualified as first order (highest quality) in the national BNDC and are located in main cities; they have all been subjected to exhaustive quality control to 
Table 2. Annual mean rates $\left({ }^{\circ} \mathrm{C}\right.$ decade $\left.^{-1}\right)$ and $95 \%$ confidence intervals, under decreasing temporal windows (5 yr intervals). Significance (Sig): ${ }^{* * *} \mathrm{p} \leq 0.001,{ }^{* *} \mathrm{p} \leq 0.01,{ }^{*} \mathrm{p} \leq 0.05$

\begin{tabular}{|c|c|c|c|c|c|c|c|c|}
\hline & Sig & MOTEDAS & Sig & Reanalysis & Sig & BEST & Sig & SDAT \\
\hline 1916_2012_97 & $* * *$ & $0.108 \pm 0.037$ & $* * *$ & $0.072 \pm 0.072$ & $* * *$ & $0.109 \pm 0.035$ & $* * *$ & $0.146 \pm 0.037$ \\
\hline 1921_2012_92 & $* * *$ & $0.101 \pm 0.039$ & $* * *$ & $0.081 \pm 0.081$ & $* * *$ & $0.106 \pm 0.038$ & $* * *$ & $0.138 \pm 0.040$ \\
\hline 1926_2012_87 & $* * *$ & $0.096 \pm 0.044$ & $* * *$ & $0.081 \pm 0.092$ & $* * *$ & $0.108 \pm 0.042$ & $* * *$ & $0.135 \pm 0.046$ \\
\hline 1931_2012_82 & $* * *$ & $0.112 \pm 0.050$ & $* * *$ & $0.094 \pm 0.106$ & $* * *$ & $0.132 \pm 0.045$ & $* * *$ & $0.155 \pm 0.051$ \\
\hline 1936_2012_77 & $* * *$ & $0.106 \pm 0.054$ & $* *$ & $0.085 \pm 0.116$ & $* * *$ & $0.131 \pm 0.048$ & $* * *$ & $0.151 \pm 0.056$ \\
\hline 1941_2012_72 & $* * *$ & $0.116 \pm 0.064$ & $* *$ & $0.102 \pm 0.131$ & $* * *$ & $0.144 \pm 0.058$ & $* * *$ & $0.158 \pm 0.067$ \\
\hline 1946_2012_67 & $* * *$ & $0.120 \pm 0.072$ & $* * *$ & $0.124 \pm 0.138$ & $* * *$ & $0.153 \pm 0.068$ & $* * *$ & $0.174 \pm 0.075$ \\
\hline 1951_2012_62 & $* * *$ & $0.177 \pm 0.075$ & $* * *$ & $0.177 \pm 0.143$ & $* * *$ & $0.203 \pm 0.066$ & $* * *$ & $0.240 \pm 0.078$ \\
\hline 1956_2012_57 & $* * *$ & $0.201 \pm 0.085$ & $* * *$ & $0.199 \pm 0.165$ & $* * *$ & $0.237 \pm 0.078$ & $* * *$ & $0.282 \pm 0.087$ \\
\hline 1961_2012_52 & $* * *$ & $0.217 \pm 0.099$ & $* * *$ & $0.216 \pm 0.182$ & $* * *$ & $0.256 \pm 0.094$ & $* * *$ & $0.330 \pm 0.094$ \\
\hline 1966_2012_47 & $* * *$ & $0.281 \pm 0.113$ & $* * *$ & $0.284 \pm 0.207$ & $* * *$ & $0.310 \pm 0.107$ & $* * *$ & $0.406 \pm 0.105$ \\
\hline 1971_2012_42 & $* * *$ & $0.388 \pm 0.123$ & $* * *$ & $0.355 \pm 0.242$ & $* * *$ & $0.381 \pm 0.124$ & $* * *$ & $0.481 \pm 0.124$ \\
\hline 1976_2012_37 & $* * *$ & $0.290 \pm 0.151$ & $* * *$ & $0.289 \pm 0.296$ & $* * *$ & $0.269 \pm 0.147$ & $* * *$ & $0.409 \pm 0.151$ \\
\hline 1981_2012_32 & * & $0.186 \pm 0.186$ & * & $0.231 \pm 0.412$ & $*$ & $0.184 \pm 0.179$ & $* * *$ & $0.309 \pm 0.180$ \\
\hline 1986_2012_27 & & $0.120 \pm 0.228$ & & $0.156 \pm 0.510$ & & $0.143 \pm 0.209$ & * & $0.250 \pm 0.243$ \\
\hline 1991_2012_22 & & $0.237 \pm 0.352$ & & $0.293 \pm 0.803$ & & $0.204 \pm 0.308$ & & $0.292 \pm 0.342$ \\
\hline
\end{tabular}

avoid the urban effect (Brunet et al. 2006, Sigró et al. 2015). On the other hand, the BEST data set website suggests that, for the period analysed in this research, the Spanish series was calculated using fewer than 20 observatories at distances of $<500 \mathrm{~km}$, and eventually using stations at $1000 \mathrm{~km}$, but no specific indication is given about stations used. The MOTEDAS_century national series is derived from a high-resolution grid, calculated with a minimum of 228 stations (in 1938) and, from 1950, using a minimum of 1000 stations $\mathrm{mo}^{-1}$.

Given that the biggest differences among versions are identified in the most recent period when the number of observations is higher (as in MOTEDAS_century), we suggest that the determining factor for the differences among versions (especially with SDAT) could be the spatial characteristics of the stations. The final series calculated from grids in MOTEDAS_century come from a more diverse spectrum of initial conditions than the others. This is the reason why we believe that the MOTEDAS_century series of mean values of annual and seasonal temperatures are more representative of thermal evolution on the Spanish mainland - because they include the high spatial variability of the land. A comparison of the trend rates of evolution using the leading data sets shows that temperatures on the Spanish mainland, as represented by the new MOTEDAS_century data set, agree with global magnitudes, and except in the 1970s, no extraordinary values have been detected. Furthermore, for the last few decades, the annual temperature trend rates on the Spanish mainland are lower than those suggested by the global rates. This finding is new and needs to be researched further.

\section{CONCLUSIONS}

The trend analysis of annual and seasonal mean temperature values obtained using the new MOTEDAS_ century grid indicate that the temperature increase during the study period (1916-2015) was not monotonic and occurred in a sequence of periods. These results are confirmed in the temporal windows approach, both at annual and seasonal scales, and also by spatial analyses of the areas affected by significant trends under increasing and decreasing temporal windows. In the former, we identified 2 rising periods and 2 pauses. These analyses show that for the last ca. 30 yr (up until 2015) the trends were not significant.

Comparison between different versions of annual and seasonal mean temperatures from the BEST, Reanalysis and SDAT databases suggest that MOTEDAS_century processing did not affect the global pattern of temperature evolution during the study period. However, larger differences were found in the most recent decades among versions, with MOTEDAS_century resulting in the lowest rates of change. We suggest that the number of stations involved in the calculation of the grids can significantly affect the final rate. Seasonal differences were detected, and revealed that 2 seasons, spring and summer, have the largest impact on the overall rise in mean annual temperatures over the Spanish mainland. 


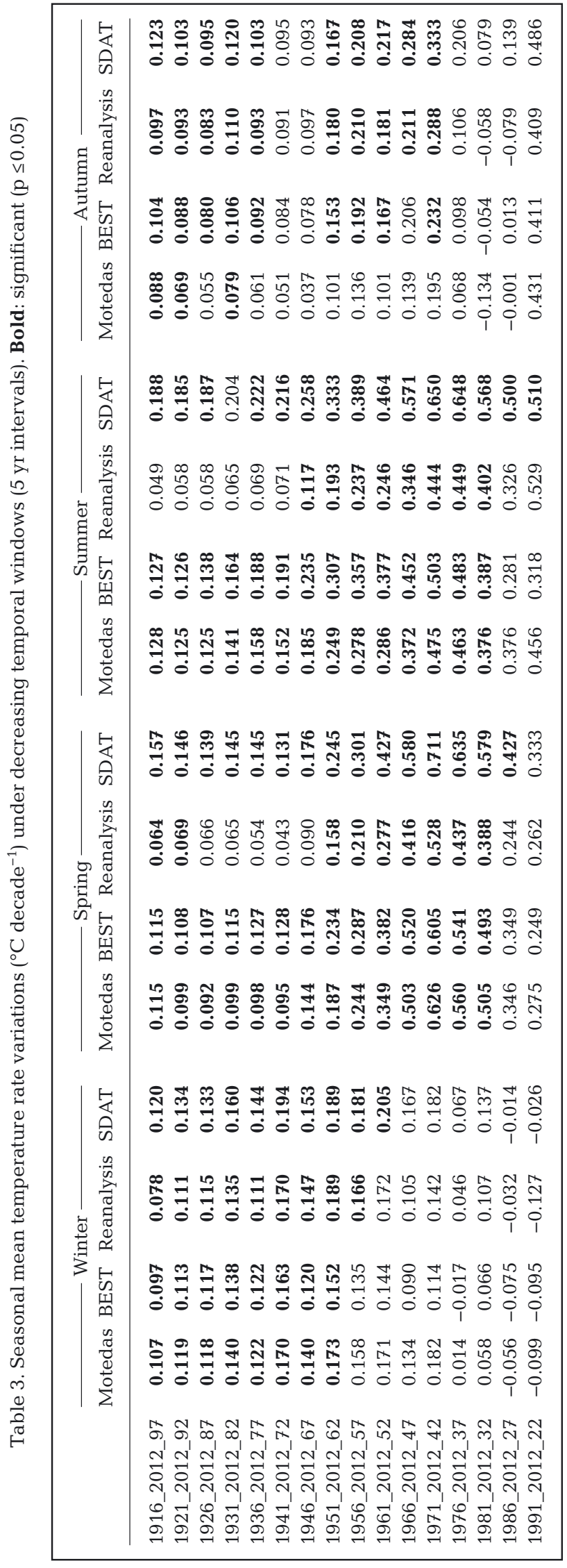

Data availability. www.clices.unizar.es; BEST: http:// berkeleyearth.org/data-new/

Acknowledgements. Gobierno de España, Ministerio de Economía y Competitividad-FEDER, Proyecto CLICES (CGL2017-83866-C3-1-R and CGL2017-83866-C3 3-R). Gobierno de Aragón, Grupo de Investigación Proceso Geoambientales y Cambio Global (E02-17R). Dhais Peña-Angulo 'Juan de la Cierva Formación' contrato (FJCI-2017-33652 MEC). Special thanks to Best Data set, Reanalyses, J Sigró (University of Tarragona, Spain) for providing the BEST, Reanalyses and SDAT series. Data from BNDC were provided by AEMET.

\section{LITERATURE CITED}

Allen MR, Dube OP, Solecki W, Aragón-Durand F and others (2018) Framing and context. In: Masson-Delmotte V, Zhai P, Pörtner HO, Roberts D and others (eds) Global warming of $1.5^{\circ} \mathrm{C}$. Intergovernmental Panel on Climate Change, Geneva

* Brunet M, Saladié O, Jones P, Sigró J and others (2006) The development of a new dataset of Spanish daily adjusted temperature series (SDATS) (1850-2003). Int J Climatol 26:1777-1802

* Brunet M, Jones P, Sigró J, Saladié O and others (2007) Temporal and spatial temperature variability and change over Spain during 1850-2005. J Geophys Res 112:D12117

* Brunetti M, Maugeri M, Monti F, Nanni T (2006) Temperature and precipitation variability in Italy during the last two centuries from homogenised instrumental time series. Int J Climatol 26:345-381

* del Río S, Herrero L, Pinto-Gomes C, Penas A (2011) Spatial analyses of mean temperature trends in Spain over the period 1961-2006. Global Planet Change 78:65-75

* del Río S, Cano-Ortiz A, Herrero L, Penas A (2012) Recent trends in mean maximum and minimum air temperatures over Spain (1961-2006). Theor Appl Clim 109:605-626

* Easterling DR, Wehner MF (2009) Is the climate warming or cooling? Geophys Res Let 36:L08706

* Folland CK, Boucher O, Colman A, Parker DE (2018) Causes of irregularities in trends of global mean surface temperature since the late $19^{\text {th }}$ Century. Sci Adv 4:eaao5297

*Foster G, Rahmstorf S (2011) Global temperature evolution 1979-2010. Environ Res Let 6:044022

* Gonzalez-Hidalgo JC, Peña-Angulo D, Brunetti M, Cortesi N (2015) MOTEDAS: a new monthly temperature database for mainland Spain and the trend in temperature (19512010). Int J Climatol 35:4444-4463

KGonzalez-Hidalgo JC, Peña-Angulo D, Brunetti M, Cortesi N (2016) Recent trend in temperature evolution in Spanish mainland (1951-2010): from warming to hiatus. Int J Climatol 36:2405-2416

* Konzalez-Hidalgo JC, Peña-Angulo D, Beguería S, Brunetti M (2020) MOTEDAS Century: a new high resolution secular monthly maximum and minimum temperature grid for the Spanish mainland (1916-2015). Int J Climatol 40: 5308-5328

Guijarro JA (2013) Tendencias de la Temperatura. In: GarcíaLega C, Valero F (eds) Fenómenos meteorológicos adversos en España. WCRP, AMV ediciones, Madrid, p 313-323

*Herrera S, Fernández J, Gutiérrez JM (2016) Update of the Spain02 gridded observational dataset for Euro- 
CORDEX evaluation: assessing the effect of the interpolation methodology. Int J Climatol 36:900-908

Jones PD (2016) The reliability of global and hemispheric surface temperature records. Adv Atmos Sci 33: 269-282

Jones PD, Lister D, Osborn TJ, Harpham C, Salmon M, Morice CP (2012) Hemispheric and large-scale landsurface air temperature variations: an extensive revision and an update to 2010. J Geophys Res Atmos 117: D05127

Kaufmann RK, Kauppi H, Mann ML, Stock JH (2011) Reconciling anthropogenic climate change with observed temperature 1998-2008. Proc Natl Acad Sci USA 108: 11790-11793

Koutsoyiannis D (2020) Revisiting global hydrological cycle: Is it intensifying? Hydrol Earth Syst Sci Discuss

KLiebmann B, Dole RM, Jones C, Bladé I, Allured D (2010) Influence of choice of time on global surface temperature trend estimates. Bull Am Meteorol Soc 91:1485-149

Loehle C (2009) Trend analysis of satellite global temperature data. Energy Environ 20:1087-1098

* Mann HB (1945) Nonparametric test against trend. Econometrica 13:245-259

McKitrick RR (2014) HAC-robust measurement of the duration of a trendless subsample in a Global Climate Time Series. Open J Stat 4:527-535

Medhaug I, Stolpe MB, Fischer EM, Knutti R (2017) Reconciling controversies about the 'global warming hiatus'. Nature 545:41-47

Montandon LOM, Fal S, Pielke RA Sr, Nigoyi D (2011) Distribution of landscape types in the global historical climatology network. Earth Interact 15:1-24

Peña-Angulo D, Cortesi N, Brunetti M, González-Hidalgo JC (2015) Spatial variability of maximum and minimum monthly temperature in Spain during 1981-2010 evaluated by correlation decay distance (CDD). Theor Appl Clim 122:35-45

Peña-Angulo D, Brunetti M, Cortesi N, González-Hidalgo JC (2016) A new climatology of maximum and minimum temperature (1951-2010) in the Spanish mainland: a com-

Editorial responsibility: Eduardo Zorita, Geesthacht, Germany parison between three different interpolation methods. Int J Geogr Inform 30:2109-2132

Peterson TC, Vose RS (1997) An overview of the global historical climate network temperature database. Bull Am Meterol Soc 78:2837-2849

Ríos-Cornejo D, Penas A, del Río S (2012) Comparative analysis of mean temperature trends in continental Spain over the period 1961-2010. Int J Geobot Res 2:45-85

Rohde R, Muller RA, Jacobsen R, Muller E and others (2013) A new estimate of the average Earth surface land temperature spanning 1753 to 2011. Geoinform Geostat: an overview 1:1

* Santer BD, Mears C, Doutriaux C, Caldwell P and others (2011) Separating signal and noise in atmospheric temperature changes: the importance of timescales. J Geophys Res 116:D22105

* Sen PK (1968) Estimates of the regression coefficient based on Kendall's tau. J Am Stat Assoc 63:1379-1389

Sigró J, Brunet M, Domokos P, Aguilar E and others (2015) Long-term temperature change over mainland Spain: an update to 2014 and reassessment of the Spanish daily adjusted temperature series (SDATS). In: Ashcroft L, Castellà M, Lehoczky A (eds) International Symposium CLIMATEES 2015. Progress on climate change detection and projections over Spain since the findings of the IPCC AR5. Book of Abstracts. Universitat Rovira I Virgili, Tortosa

Slivinski LC, Compo GP, Whitaker JS, Sardeshmukh PD and others (2019) Towards a more reliable historical reanalysis: improvements for version 3 of the Twentieth Century Reanalysis system. Q J R Meteorol Soc 145:2876-2908

Staudt M, Esteban-Parra MJ, Castro-Díez Y (2007) Homogenisation of long-term monthly Spanish temperature data. Int J Climatol 27:1809-1823

Strangeways I (2010) Global measuring temperatures. Cambridge University Press, Cambridge

Thorne PW, Parker DE, Christy JR, Mears CA (2005) Uncertainties in climate trends: lessons from upper-air temperature records. Bull Am Meterol Soc 86:1437-1442

Tung KK, Chen X (2018) Understanding the recent global surface warming slowdown: a review. Climate 6:82

Submitted: August 31, 2020; Accepted: November 9, 2020

Proofs received from author(s): December 30, 2020 